\title{
An examination of the mechanisms underlying the effects of physical activity on brain and cognition
}

\author{
A review with implications for research
}

\author{
José Marmeleira
}

Received: 27 March 2012 / Accepted: 7 October 2012 /Published online: 23 October 2012

(C) European Group for Research into Elderly and Physical Activity (EGREPA) 2012

\begin{abstract}
Physical activity positively influences brain health and cognitive functioning in older adults. Several physiological and psychological mechanisms have been identified to underlie such a relationship. Cardiovascular fitness is accompanied with changes in mechanisms such as cerebral blood flow, neurotrophic factors, neurotransmitter systems and neural architecture that have themselves been associated with cognitive performance. Factors associated with exercise such as arousal, mood and self-perception of competence seem also to influence cognitive performance. Other explanation for the benefits of exercise in cognition, results from the fact that the performance of motor skills involve an important cognitive component (e.g., executive functions and information processing speed). Evidence of brain plasticity and behavior has been provided from studies where animals are exposed to enriched or complex environments. Exposure to such paradigms in which physical activity plays an important role has been found to influence various aspects of brain function and structure. Studies using neuroimaging techniques have established a link between the acquisition of different motor skills and the occurrence of neuroplasticity in human adults. This literature review indicates that the type of exercise and its specific perceptual and cognitive characteristics may influence cognitive performance. However, most of the research has been focused on self-paced movements or
\end{abstract}

\footnotetext{
J. Marmeleira $(\triangle)$

Department of Sport and Health, University of Évora,

Pavilhão Gimnodesportivo, Prolongamento da

Rua de Monsaraz, 14,

7000-727 Évora, Portugal

e-mail: jmarmel@uevora.pt

J. Marmeleira

Research Center in Sports Sciences, Health Sciences

and Human Development (CIDESD),

Vila Real, Portugal
}

automatized skills and few intervention studies have examined the results of merging exercise and cognitive training in a single program. An important scientific challenge for the coming years is to design exercise programs capable of mobilizing several type of mechanisms underlying the effects of physical activity on brain and cognition.

Keywords Physical activity $\cdot$ Aging $\cdot$ Cognition . Neuroplasticity

\section{Introduction}

Physical activity has the potential to intervene positively in several perceptual, cognitive, and physical abilities as well as health factors. The benefits of physical activity seem to have a singular expression among the older population because it is well known that aging is associated with noticeable functional changes that can impact activities of daily living. Research on the effects of physical activity in cardiovascular function, muscular function, body composition and health conditions (e.g., hypertension and diabetes) is abundant, and its positive influences are now well established [22]. At the same time, a growing body of work has been dedicated to the study of the relationship between physical activity and cognition. This emergent line of investigation has reported promising findings, particularly in the older population. There is now strong evidence, including from several longitudinal studies, that physical activity and exercise have a significant impact on several psychological parameters [22]. Research has generally shown that older adults who are more physically active exhibit better cognitive performance than do older adults who are less physically active $[10,35,42,119]$. Meta-analytic reviews show that the effect size of exercise in cognition frequently ranges from small to moderate $[24,44]$. These benefits of exercise 
include, but are not limited to the following: greater efficiency in information processing [44,73], enhancement of attention capacity $[59,108]$, better performance on tasks that demand visual-spatial processing [116], benefits for executive-control processes [24] and greater psychomotor speed [119].

Studies in animals and humans have investigated the physiological, neurobiological and psychological bases that account for the positive associations between physical activity and cognition. At the physiological and neurobiological levels of analysis, mechanisms that have been proposed to justify the exercise-cognition relationship include cortical structure (neurogenesis and synaptogenesis), cerebral metabolism, neurotransmitters, neurotrophic factors, oxygen availability, glucose regulation, and oxidative stress $[27,43]$. At the cognitive and behavioral levels of analysis, important roles has been attributed to executive control processes [24], to attentional resources [104] or to effects on mediating variables known to affect cognition, like arousal, self-efficacy, mood or depression $[90,125]$.

In this article, we first focus on the factors that support a positive relationship between physical activity and cognition. Physiological and psychological mechanisms and behavioral interventions are reviewed from animal and human studies. Subsequently, we analyse the implications of the reviewed literature for the research about the effects of exercise on the brain and cognition. Special emphasis is given in the last section to the potential effects of different types of exercise. Throughout the article physical activity refers to body movement produced by the contraction of skeletal muscles that results in energy expenditure above resting levels [18]. Exercise refers to a subset of physical activity that is planned, structured, and repetitive and has as a final or an intermediate objective the improvement or maintenance of one or more components of physical fitness [18]. Physical fitness is a set of attributes that are either health-related (e.g., cardiovascular fitness) or skill-related (e.g., reaction time).

\section{Aerobic fitness and cognition}

Probably, the cardiovascular fitness hypothesis has been the most recognized hypothesis for explaining the positive association between physical activity and cognition. It suggests that the gains in cardiovascular (aerobic) fitness achieved through regular participation in physical activity mediate cognitive performance benefits $[21,45,127]$. The enhancement of aerobic fitness is thought to be accompanied with changes in the underlying mechanisms such as cerebral blood flow $[38,122]$, brain-derived neurotrophic factor (BDNF) $[132,139]$ and cerebral structure $[25,26]$ that have themselves been associated with cognitive performance.
The magnitude of the training effect on older adults' cardiovascular condition differs among studies, and it has been suggested that the amount of physical improvement engendered is related to the degree of change in mental abilities. It has been pointed out $[9,125]$ that studies showing positive effects of exercise in cognition have tended to demonstrate large changes in individual pre- to postintervention scores for aerobic fitness. Findings from several cross-sectional and other observational studies also showed that aerobically fit adults performed better on cognitive tests than did less fit adults $[20,39,60,127]$.

Nevertheless, some studies have failed to obtain evidence for the relationship between aerobic training and cognitive function. Panton et al. [101] assigned older adults (7079 years) to aerobic training, strength training and control conditions. Neither form of exercise was related to subjects' reaction times or movement speed. Furthermore, an important meta-analysis [24] found no relationship between the magnitude of improvements in $\mathrm{VO}_{2 \max }$ and the effect of exercise interventions on neurocognitive function. Correspondingly, in the study by Etnier et al. [45], a meta-regression analysis did not support the cardiovascular fitness hypothesis.

\section{Cerebral circulation hypothesis}

Because oxygen and glucose are not stored in the brain, the vascular system must quickly respond to environmental demands on the central nervous system (CNS) by resupplying activated brain areas with these substances [34]. Despite representing only $2 \%$ of the total body weight, the brain uses $20-25 \%$ of the total body oxygen and $25 \%$ of the total body glucose to meet the brain's energy needs and for metabolism and turnover of neurotransmitters [47]. Given this fact, the cerebral circulation hypothesis suggest that chronic exercise results in an enhancement of oxygen and glucose transportation to the brain, which results in better cognitive performance because of the increased resources available to the cerebral environment $[21,45]$. This is particularly important for older adults because there is strong evidence that age is inversely related to efficient delivery of blood to the CNS $[118,123]$. Among the various mechanisms that have been pointed to as being responsible for the age-related decrement in blood flow are an increase in whole-blood viscosity and plasma viscosity, loss of elasticity and progressive fibrosis of cerebral vasculature $[1,93]$.

Marks et al. [83] demonstrated that cerebral blood flow and cognitive function is maintained in aerobically active older adults; McFarland [88] showed that cognitive decline observed in older adults was similar to impairments seen in younger individuals under conditions of hypoxia. It was reported [106] that older adults who are physically active 
or are still engaged in physically demanding work sustained more constant cerebral blood flow levels than those that who were classified as physically inactive; furthermore, active individuals and workers also scored better on cognitive testing compared to the inactive ones. Others have concluded that individuals who retired and led a sedentary lifestyle were at an increased risk of cerebrovascular disease with associated cognitive impairment [106]. Finally, some studies showed small but significant improvements in cognitive performance (e.g., memory and reaction time) following supplemental administration of oxygen [95,112] or glucose $[81,82]$.

\section{Neurotrophic stimulation hypothesis}

There are various studies of animal models that have shown that PA induces BDNF and other growth factors consistent with improved neuronal activity, synaptic structure, and neuronal plasticity $[34,135]$. Findings in human samples showed that a single bout of exercise can increase plasma BDNF concentration [135]; a 5-week endurance training also led to an increase in both basal as well as the endexercise BDNF [140]. Specifically, BDNF supports the health and functioning of glutaminergic neurons, stimulates neurogenesis and improves learning and mental performance [27].

Neurotrophins are expressed throughout the brain, and some of the highest levels have been found in the hippocampus, an area of the brain important in learning and memory $[27,96]$. In addition to increasing the expression of neurotrophins in the brain, exercise increases levels of other types of trophic factors derived from endocrine tissues. Investigation in animal models demonstrated that insulin-like growth factor-I (IGF-I) levels increase in both the periphery and in the brain after exercise [17]. IGF-I might be an upstream mediator of BDNF gene regulation, neurogenesis and the ability of exercise to protect the brain from injury $[17,27]$.

It seems that exercise mobilizes gene expression profiles that would be predicted to benefit brain plasticity processes [27]. The effects of genes encoding neurotrophins and other proteins predict that exercise could regulate downstream anatomical changes that support brain plasticity [27]. The idea that neurogenesis also occur in the adult brain [2] was first received with scepticism by the scientific community. At present, it is well established that the mammalian adult brain can produce new neurons $[53,128,129]$. At least one study [41] demonstrated that the human hippocampus also retains its ability to generate neurons throughout life. The dentate gyrus, a hippocampal sub-region associated with memory and learning, is the primary region where the neurogenesis phenomenon takes place $[63,75]$. Recent studies have suggested that neurogenesis can also be found in neocortical association areas such as the prefrontal and posterior parietal cortices of nonhuman primates $[54,55]$.

Physical activity is one of the factors that positively affect adult neurogenesis [75,129]. Colcombe et al. [26] showed that significant increases in brain volume, in both grey and white matter regions, were found as a function of fitness training for subjects who participated in an aerobic fitness training but not for subjects who participated in a stretching and toning (nonaerobic) control group. Recently, it was reported that aerobic exercise training is effective at reversing hippocampal volume loss in late adulthood, which is accompanied by improved memory function [40].

\section{Neurotransmitter systems}

The degeneration of neurotransmitter systems, primarily the dopaminergic system, may contribute to age-related gross and fine motor declines as well as to higher cognitive deficits [115]. Age-related working memory impairment was related to reduced prefrontal cortex dopaminergic transmission caused by decreased dopamine synthesis in the prefrontal termination region [94].

Directly testing of neurotransmitters changes in humans is not possible. As a result, animal studies have been carried out to support the claim that exercise induces changes in brain concentrations. Researchers have focused their efforts on the study of noradrenaline and dopamine. There is some evidence of increased dopamine concentrations during and following acute exercise and as a result of chronic exercise. Research on acute exercise has demonstrated increases particularly in the brainstem and hypothalamus [92]. There seems to be a "threshold speed" above which neurotransmitter release begins [58,92]. Chronic exercise shows region-specific effects with increases in the hypothalamus and midbrain concentrations but decreases in the prefrontal cortex, hippocampus and striatum [91].

In general, studies have shown either a decrease or no significant effect of chronic exercise on noradrenaline concentrations in the whole brain, although there are some regional variations (especially in the hypothalamus) $[91,92]$. There is, however, unequivocal evidence for increased catecholamine turnover in the brain during exercise [89]. Increased concentrations of catecholamine metabolites (the by-products of catecholamine synthesis and usage) have been found in the brain during and following acute exercise. As such, it is reasonable to state that exercise induces increased catecholaminergic activity in the brain during activity [89].

Taken together, animal studies have provided evidence that the central dopaminergic, noradrenergic, and serotonergic activity, release, and metabolism are influenced by 
exercise [90]. The results seem to be more consistent for neurotransmitter response during exercise than for longterm adaptations. Nevertheless, the studies in this research area are scarce and have been marked by technological limitations (e.g., measurements in the synapses are not yet possible). An important question to be answered is how changes in the synthesis and metabolism of neurotransmitters as a result of exercise can influence cognition. One of the possible answers is that it might follow an indirect pathway: neurotransmitter changes may underlie most of the impact of exercise in reducing depressive symptoms both in healthy and clinical populations [33]. Hence, associations between depression and cognitive decline have been observed in several studies of older adults $[50,109]$.

\section{Cognitive energetics, arousal and self-efficacy}

It has been hypothesized that declines in mental and physical health, regardless of age, result from insufficient physical and mental challenge and that controlled and repeated challenge, either physical or mental, builds up the resources and the "mental toughening" needed to meet environment demands and cope with stress [29,30]. According to Dienstbier [29], data from both non-human and human studies shows that better performances across a variety of tasks appear to be associated with increased catecholamine levels (adrenaline, noradrenaline, and dopamine) and quicker return to baseline rates following stressful manipulations.

Extending this perspective, Tomporowski [125] considers that older adults' responses to challenging tasks are predicted to lead to both short-term and long-term physiological benefits as the increase in the levels of arousal and energy set the stage for individuals to meet and overcome task demands. An individual's newly acquired history of success, in turn, motivates him or her to continue to engage in challenging activities. The continued performance of challenging activities by older adults would be expected to lead to practice and its associated maintenance of skilled behavior [125]. Within this framework, the level of difficulty of the activities that integrate the intervention programs for older adults is an important issue [51]. Training tasks (both physical and cognitive) that are much too difficult or much too easy will lead to lower levels of arousal and motivation and thus substantially reduced learning. The learning rate would be at a maximum when the task is challenging yet still doable [56] as it is evidenced in the well-known Yerkes-Dodson law [138], which predicts that learning is an inverted U-shaped function of arousal level.

Frequently, older adults develop low perceptions of their control and competence, with negative consequences on their motivation $[86,125]$. Thus, the benefits of physical and mental training might reside more in changed beliefs than in cognitive abilities per se [19]. One important aspect of the perceived control over one's life is the construct of self-efficacy. Self-efficacy is concerned with the individual's beliefs in his or her capabilities to execute necessary courses of action to satisfy situational demands [6]. According to McAuley and Elavsky [86], mastery experiences (performance accomplishments) are the most potent source of self-efficacy beliefs, often providing objective evidence relative to what constitutes a success or a failure. Self-beliefs of efficacy can enhance or impair performance through their effects on the cognitive, affective, or motivational intervening processes; more efficacious individuals approach more challenging and varied tasks [7]. It has been shown that selfefficacy is a significant predictor of exercise adherence $[87,98]$ and that it can be also a consequence of exercise participation [86]. The role of self-efficacy for exercise participation (adherence, maintenance and effort expended) could indirectly influence cognitive function, given the known effects of physical activity on cognition. Also, it has been hypothesized that efficacy may play a mediating role in the relationship between physical activity and fitness and cognitive function inasmuch as fitter, more active, and more efficacious older adults are likely to demonstrate less anxiety in challenging cognitive situations, thereby performing better than their less active, less fit, and less efficacious counterparts [86]. Further investigation is needed to better understand the role that exercise self-efficacy plays in the exercise-cognitive function relationship.

\section{Cognitive complexity and cognitive training}

Some types of exercise require demanding information processing, and it is reasonable to consider that their practice over time is also a form of cognitive training. Accordingly, it has been hypothesized that the cognitive complexity level of work and leisure-time activities could affect older people's intellectual functioning [113]. It is widely believed that keeping mentally active will prevent age-related mental decline [111]; from a neurobiological perspective, this notion states that the use of neurons and neuronal networks prolongs the efficiency of CNS activity during life $[117,121]$. Some longitudinal studies have provided support to the "use it or lose it" hypothesis. Zunzunegui et al. [141] reported that few social ties, poor integration, and social disengagement are risk factors for cognitive decline among community-dwelling older persons. Others have found that higher frequencies of participating in activities like reading, playing chess, and completing crosswords were related to slower declines in perceptual speed [52]. Even in old age, working out on a regiment of substantively complex tasks appears to build the capacity to deal with the intellectual challenges that complex environments provide [113]. 
There is also a growing body of evidence of positive effects of programmed cognitive training at a behavioral and functional level. In a frequently cited work, Ball et al. [4] enrolled 2,800 subjects in training programs and reported benefits on the specific abilities trained (speed of processing, memory and reasoning). Results from other study [126] provide evidence that even brief periods of increased cognitive training (10-12 weeks) can improve older adults' problem solving and flexible thinking. When the additional effort required by more cognitive effort tasks is rewarded (e.g., by the beneficial effect associated with learning a new skill) it is possible that people become more motivated to further develop these capacities.

In a controlled clinical trial, older adults randomized to cognitive speed-of-processing training experienced improvements in a visual attention test (useful field of view test, $\mathrm{UFOV}^{\circledR}$ ) [3] which were maintained over a 5-year period relative to controls [134]. Results by Edwards et al. [36] indicate that the cognitive speed-of-processing training not only improves processing speed, as indicated by performance on the UFOV ${ }^{\circledR}$, but also transfers to certain everyday functions, as indicated by improved performance on timed instrumental activities of daily living (e.g., quickly finding a telephone number). Furthermore, it was shown that the enhancement of processing speed is protective against declines in health-related quality of life across 5 years $[136,137]$ and against mobility declines among older drivers [37].

\section{Environmental enrichment}

Environmental enrichment is an experimental model in which animals are housed in conditions that potentiate social interactions and sensory and motor stimulation $[107,114]$. The "use it or lose it" hypothesis is also supported by this research paradigm, which provides evidence that stimulating and challenging habitats are beneficial to the cognitive functioning of laboratory animals $[14,66,132]$. Thus, as a result of living in an enriched environment, the brains of animals undergo molecular and morphological changes leading to improvements in learning and memory. Mediating mechanisms engendered by enriched environments and training in behavioral tasks includes increased dendritic branching and synaptogenesis, changes in supportive glial cells, addition to the brain's capillary network, the development of new neurons, and a cascade of molecular and neurochemical changes [70].

Some authors support the hypothesis that environmental enrichment and exercise affects brain neuronal circuitry in similar ways, including the regulation of growth factors, neurogenesis and structural changes, which regulate behavioral plasticity $[11,27,130]$. Others consider that environmental enrichment and exercise affect different phases of the neurogenic process in distinct ways: the former seems to increase the likelihood of the survival of new cells, whereas the latter increases the level of proliferation of progenitor cells [80]. Nevertheless, clear conclusions on this issue are difficult to make because in some studies more opportunities for physical activity are also included as part of the environmental enrichment [64].

The type of exercise is another important issue that has been debated in environmental enrichment paradigms. Some research found that exercise characterized by unskilled motor movements increased capillary density without a significant change in synapse number, whereas motor skill learning induced synaptogenesis in higher-order brain regions involved in motor learning with no change in capillary density $[14,66,67]$. Klintsova et al. [68] reported that while motor skill training (obstacle course) enhanced performance on a number of subsequent behavioral tasks such as parallel bars, rope climbing, and rotarod, motor activity alone such as walking in a closed alley had little effect on performance. Other studies, however, have found a positive association between running and neurogenesis in young and old animals, which translated into improvements in behavioral tasks $[129,131]$. There seems to exist also a potential relationship between social interaction and exercise on brain function and cognition. Thus, a recent study showed that the effects of exercise on hippocampal neurogenesis were substantially delayed and reduced for a group of socially isolated rodents compared with animals that were housed in a group setting [120]. Future studies should examine this issue in humans.

Environmental enrichment research has been mostly done on rodents, but similar effects have been documented in primates [69]. Direct research in humans has been limited because it requires histological study of the brain. However, a study that involved the autopsy of human brains [62] was consistent with the environmental enrichment research results in animals and suggested that dendritic systems in humans function as a sensitive indicator of an individual's (a)vocational activities (education had a consistent and substantial effect such that dendritic measures increased as educational levels increased). Taken together, findings related in this type of research provide a biological explanation for the positive effects produced by physical and mental activity on different cognitive functions in older adults and also for the reduction in the risk of developing neurodegenerative disorders $[23,114]$.

\section{Transfer of learning}

Transfer of learning is another factor that should be considered in the analysis of the association between the regular practice of exercise and the individual's functional capacity. 
In the context of motor learning, Magill [79] defines the transfer of learning as the influence of previous experiences in a new context or on learning a new skill. In the tradition of the "identical elements theory" of Thorndike and Woodworth [124], Magill considers two hypotheses to explain why transfer of learning occurs. The skills components hypothesis assumes that the transfer of learning occurs because the components of the skills (e.g., its kinematics characteristics) and/or the context in which the skills are performed are similar. The similarity of the cognitive processes hypothesis posits that transfer occurs primarily because of similarities between the amount and types of cognitive processes (e.g., engaging in problem-solving activity, rapid decision-making, attention control, or the dualtask functioning) required by the two skills or two performance situations.

In the domain of sports psychology, some studies have demonstrated that skill changes associated with sports practice are transferable to specific cognitive abilities The results of a recent meta-analysis [133] that examined the relationship between expertise in sports and measures of cognition gave some support to the similarity of the cognitive processes hypothesis. It was found that interceptive sport types (e.g., squash, tennis) had largest effects on measures of processing speed and attention (e.g., divided attention) than closed, self-paced sports (e.g., golf and swimming). A recent study showed a beneficial effect of playing tennis on the collision avoidance skill of 70 - to 80 -year-old tennis players [78]. Also, it was shown that older adults with expertise in orienteering activities seem to develop attentional skills that withstand the age-related changes of some aspects of visual attention [103].

In the driving-related literature, two recent experimental studies $[84,85]$ used an exercise program for older drivers supported in the hypothesis that positive transfer of learning occurs primarily because of similarities between the amount and types of cognitive processes required by the performance situations. For instance, it was hypothesized that incorporating tasks in the exercise program that intend to enhance speed of behavior could have a higher impact on the individual's capacity to respond quickly to environmental stimuli during actual driving. The authors reported that improvements resulting from the exercise intervention took place on several measures of visual attention, behavioral speed, and multitask processing; this was a very positive outcome given that motor learning frequently show a great specificity with little generalization to related tasks or new environments [56].

Research has also shown that transfer of learning can occur on dual-task conditions using a variable priority training technique [71,72]. In this procedure, participants are required to vary their response priorities between the two tasks, whereas in the more typical fixed priority condition, attention was given equally to the tasks. The greater improvement obtained under the variable priority condition suggests that learning to modulate attention may be crucial in the acquisition of task coordination skills.

Starting from these promising findings, it is necessary to continue to investigate which cognitive abilities subserved by the CNS are malleable in response to the participation in exercise and to what extent they are transferable for activities of daily living. The mode of exercise is an important issue in this field, as it is possible that different exercise types impose characteristically different sets of mental demands upon the practitioner, targeting different perceptive and cognitive abilities and giving distinctive contributions for the functional capacity of older adults.

\section{Implications for research on the effects of exercise on the brain and cognition}

In the next paragraphs, the implications of the reviewed literature for the orientation of future research on the area are discussed.

Much research has been focused on the effects of aerobic fitness on measures of cognitive function. Thus, the enhancement of aerobic fitness (the cardiovascular fitness hypothesis) is very often considered as responsible for the enhancement of cognitive functioning that accompanies the practice of PA due to its influence in underlying mechanisms such as cerebral blood flow, BDNF and cerebral structure $[26,127]$. This paradigm of investigation is likely to change in the next years, especially because important meta-analytic studies have failed to obtain strong evidence for the relation between aerobic fitness and cognitive function $[24,45]$, indicating that the underlying mediators of this relationship have yet to be fully identified [45].

Studies that have compared the individual and combined effects of physical and mental exercise interventions reported cognitive benefits to be larger with the combined cognitive and physical training paradigms [46,99]. Efforts should be taken to extend this line of investigation and to examine if the effects of exercise that merge physical and cognitive stimulation might transfer to other tasks of daily living in older adults. As we have seen before, some studies have already provided a positive answer to this question, namely in the context of driving $[84,85]$. It is desirable that more research be conducted to examine the general effects of exercise interventions planned to stress not only physiological systems, but also perceptive and cognitive mechanisms. For example, it has been proposed that exercise that results in gains in cardiorespiratory fitness leads to benefits in tasks with a substantial frontal-lobe-dependent executive control component $[24,74]$. These are the cerebral areas that exhibit the largest age-related declines and are also the ones 
that show the largest exercise or fitness-related improvements. Tasks that are included in the executive functioning umbrella include those involving the use of information retained in working memory, simultaneous execution of multiple tasks, task switching, and inhibition of an ongoing or prepotent response. Considering these characteristics, the greatest gains in executive functioning might be achieved if the exercise training stimulates aerobic capacity (and by this means promoting physiological adaptations such as higher blood perfusion and neurotransmitters turnover) and also incorporate behavioral tasks that directly stimulate executive control components (e.g., planning, inhibition and task switching).

Research has been trying to determine whether some particular causes could have broad effects on many aspects of cognitive functioning. This is an appealing idea, as the identification of such causes might support the design of interventions that translate into a broader range of positive consequences in the individual's functional capacity. One hypothesis that has been proposed is that all components of information processing decline at approximately the same rate, independently of task complexity and task types [12] leading to the conceptualization of a model that held that age differences in the performance of cognitive tasks can be explained by age differences in the speed of processing [110]. In this view, it is reasonable to consider that the improvement of information processing speed has the potential to impact the general cognitive ability in older adults, leading to positive effects on their functional status, independence and quality of life [36,100]. This was already shown in the cognitive training literature [5], and recent studies have also reported positive effects of exercise programs on the information processing speed of older adults $[84,85]$. Future research using longitudinal designs is needed to examine which exercise characteristics could improve information processing speed in older adults and if this hypothetical improvement has a large impact on the individual's functional abilities.

An interesting event associated with aging is increased cautiousness or a shift in the speed-accuracy trade-off [57]. This change probably contributes to the well-established age-related tendency for slowness of perceptual, motor, and cognitive processes [13,28,97]. In chronometric studies, models of the speed-accuracy trade-off indicate that there will be large costs in reaction time for small gains in accuracy at high levels of performance. Thus, relatively small differences between younger and older adults in their response criteria could produce substantial differences in reaction time [57]. Perhaps, if one could change this extracautiousness behavior of older people (typically, they emphasize accuracy rather than speed), their performance differences compared with younger adults could be reduced. Previous work has shown that this is possible: after speed- behavior training in a memory search task, equivalent accuracies were achieved for young and old adults and the response time differences between the groups present at baseline were substantially reduced [8]. In this experiment, subjects were trained with a deadline procedure in which they were required to constantly increase the speed with which they performed the task. Thus, these data suggest a more substantial improvement in performance related to speed of responding for the old than for the younger adults when exposed to appropriate training. The same kind of strategy should be tested using exercise programs, which regularly include motor activities dependent on reaction and execution times. Marmeleira et al. [85] provided evidence that exercise could be a good strategy to change the conservative relationship between speed and accuracy that is typical in older adults. In their experimental study, the need to quickly choose between different motor responses according to the stimuli presented was recurrently trained during the exercise sessions. At the end of the intervention, significant differences between the group of older adults that participate in the exercise program and the control group were found in a choice reaction time task, while accuracy stayed very close to the baseline values for both groups.

The type of exercise is a factor that should be examined more closely given its potential to induce specific effects in the brain and in perceptual and cognitive abilities. The investigation on the relationship between physical activity and cognition in older adults has mainly examined the effects of self-paced movements or automatized skills (e.g., walking), and frequently the type of activity is considered mainly on its effects on aerobic fitness. However, based on the literature reviewed, it seems reasonable to hypothesize that exercises which exert large cognitive demands (e.g., involving learning processes, executive control, information processing speed) could have a higher impact on cognition. For instance, could an activity like dance exert a differential influence in neuroplasticity in comparison with walking? Can the learning of new motor skills or the retraining and improvement of older ones induce positive changes in the brain and in cognition? This kind of questions are pertinent if one considers the idea that nothing speeds brain atrophy more than being immobilized in the same environment and that the monotony undermines our dopamine and attentional systems crucial to maintaining brain plasticity [31]. As observed previously in this article, it is well documented that an enriched environment and cognitive training can lead to improved learning and memory as well as structural and morphological changes in the brain [105]. Experimental animal studies have shown that exercise associated with planning and execution of complex movements is related to changes in brain structure [61]. Some studies with animals demonstrated that exercise characterized by unskilled motor movements can increase 
capillary density without a significant change in synapse number, whereas motor skill learning induce synaptogenesis in higher-order brain regions involved in motor learning with no change in capillary density $[14,15,67]$.

In recent years, with the advent of sophisticated neuroimaging techniques, several studies were able to establish a link between the acquisition of different skills and the occurrence of neuroplasticity in human adults. For example, grey matter volume differences were reported for motor, auditory, and visual-spatial brain regions when comparing professional musicians (keyboard players) with a matched group of amateur musicians and non-musicians [49]. In an elegant study, it was shown that the posterior hippocampi of people with extensive navigation experience (taxi drivers) were significantly larger relative to those of control subjects [80]. In another frequently cited study, it was demonstrated that young adults who have learned to juggle, show a transient and selective structural change in brain areas that are associated with the processing and storage of complex visual motion [32]. The findings from this last study were reproduced in older adults [16]. Further research in humans is needed to understand the influence of neuromotor exercise training in brain health and cognition, which incorporates motor skills such as balance, coordination, agility, and proprioceptive training [48]. Moreover, some forms of neuromotor exercise also contain an important aerobic component, which is also a factor considered to influence brain health and cognitive functioning.

Research has already started to reveal that different types of exercise have specific repercussions on the brain and cognition. A comparison between a group of internationally competitive judo players and a group of healthy controls showed a significantly higher grey matter tissue density in the brain areas of judo players [61]. Another study [102] reported that blood volume in the dentate gyrus (the only hippocampal sub-region that supports adult neurogenesis) of adults, assessed by magnetic resonance imaging as an in vivo marker of neurogenesis, increased significantly over a 3-month period of aerobic exercise. Moreover, this increase in dentate gyrus blood volume was significantly correlated with gains in maximal aerobic capacity, and an improvement in short-term memory. These results were corroborated in a recent study that concluded that aerobic exercise training (walking program) is effective at reversing hippocampal volume loss in late adulthood, which is accompanied by improved memory function [40]. Important findings have been also reported in the research about alternative forms of exercise that intend to simultaneously target mind and body (e.g., tai-chi and yoga). Kerr et al. [65] suggested that tai-chi may elicit long-term plasticity in primary sensory cortical maps, while others have demonstrated improvements in both physical and psychological domains [76,77]. Mindbody exercise also has a meditative aspect, which has been proven very effective in lowering stress and is likely to preserve memory and the hippocampal neurons [31].

Given all the evidence, future work should explore a line of investigation where the focus of attention is on the potential for different exercise programs to mobilize/stimulate a broad range of abilities (i.e., physical, perceptual and cognitive) and, therefore, to produce higher benefits on functional capacity, chronic disease risk, and quality of life of older adults.

\section{Summary}

The brain is remarkably plastic at functional and anatomical levels in response to experience, and evidence has accumulated that physical activity preserves brain health and cognition. Animal and human studies support that several physiological and psychological mechanisms underlie the relationship between physical activity and cognitive functioning.

Cardiovascular fitness has been considered as a major factor responsible for the positive influence of physical activity in brain and cognition. Important mechanisms such as cerebral oxygen and glucose availability, BDNF, neurotransmitters and cerebral structure have been hypothesized to accompany changes in cardiovascular fitness. Nevertheless, some studies have failed to obtain strong evidence for the relation between aerobic fitness and cognitive function.

Some types of cognitive training for older adults have shown benefits that were sustained for relatively long periods of time. Also, the regular participation in complex occupational activities seems to benefit older people's intellectual functioning. Considering that cognition plays an important function in performing motor skills, it is reasonable to consider that cognitive training also results from the regular practice of exercise. This seems especially true for those types of exercise that rely on high cognitive effort. Important evidence of the influence of physical activity in brain plasticity and behavior has been provided also from studies where animals are exposed to enriched or complex environments. Exposure to such environments in which physical activity plays an important role has been found to influence various aspects of brain function, neurochemistry, and neural architecture.

The available scientific evidence supports the hypothesis that maintaining an intellectually stimulating and physically active lifestyle promotes successful cognitive aging. Until now, the great majority of studies have focus their analysis on single factors thought to influence cognitive function in older adults. The few human intervention studies that have examined the combined influence of multiple lifestyle factors (e.g., merging exercise and cognitive training) provided evidences of the potential of such an approach. This view is 
related with another important issue: the role of different types of exercise in cognitive functioning and overall functional capacity of older adults. Using sophisticated neuroimaging techniques, several studies were able to establish a link between the acquisition of different motor skills or the practice of specific types of exercise and the occurrence of neuroplasticity in human adults.

Mode of exercise and its specific perceptual and cognitive characteristics/demands may influence the learning and mental performance obtained. However, the investigation on the relationship between physical activity and cognition in older adults has mainly examined the effects of self-paced movements or automatized skills. The body of work examining the effects of specific types of exercise/sports on the functional capability of older adults should be expanded in the future. Hence, an important scientific challenge is to design exercise programs capable of mobilizing several type of mechanisms underlying the effects of physical activity on brain and cognition.

Disclosure of interest The author declares that have no conflicts of interest concerning the article An examination of the mechanisms underlying the effects of physical activity on brain and cognition: a review with implications for research.

\section{References}

1. Ajmani RS, Metter EJ, Jaykumar R, Ingram DK, Spangler EL, Abugo OO, Rifkind JM (2000) Hemodynamic changes during aging associated with cerebral blood flow and impaired cognitive function. Neurobiol Aging 21(2):257-269

2. Altman J (1962) Are new neurons formed in the brains of adult mammals? Science 135:1127-1128

3. Ball K, Owsley C (1993) The useful field of view test: a new technique for evaluating age-related declines in visual function. $\mathrm{J}$ Am Optom Assoc 64(1):71-79

4. Ball K, Berch DB, Helmers KF, Jobe JB, Leveck MD, Marsiske M, Morris JN, Rebok GW, Smith DM, Tennstedt SL, Unverzagt FW, Willis SL (2002) Effects of cognitive training interventions with older adults: a randomized controlled trial. JAMA 288(18):2271-2281

5. Ball K, Edwards JD, Ross LA (2007) The impact of speed of processing training on cognitive and everyday functions. J Gerontol B Psychol Sci Soc Sci 62(Spec No 1):19-31

6. Bandura A (1986) Social foundations of thought and action: a social cognitive theory. Prentice Hall, Englewood Cliffs, NJ

7. Bandura A (1989) Regulation of cognitive processes through perceived self-efficacy. Dev Psychol 25(5):729-735

8. Baron A, Mattila WR (1989) Response slowing of older adults: effects of time-limit contingencies on single- and dual-task performances. Psychol Aging 4(1):66-72

9. Bashore TR, Goddard PH (1993) Preservative and restoring effects of aerobic fitness in the age-related slowing of mental processing speed. In: Cerella J, Rybash J, Hoyer W, Commons ML (eds) Adult information processing: limits on loss. Academic, San Diego, CA

10. Baylor AM, Spirduso WW (1988) Systematic aerobic exercise and components of reaction time in older women. J Gerontol 43 (5):121-126
11. Biernaskie J, Corbett D (2001) Enriched rehabilitative training promotes improved forelimb motor function and enhanced dendritic growth after focal ischemic injury. J Neurosci 21(14):5272-5280

12. Birren JE, Fisher LM (1995) Aging and speed of behavior: possible consequences for psychological functioning. Annu Rev Psychol 46:329-353. doi:10.1146/annurev.ps.46.020195.001553

13. Birren JE, Renner VJ (1977) Research on the psychology of aging: principles and experimentation. In: Birren JE, Schaie KWE (eds) Handbook of the psychology of aging. Van Nostrand-Reinhold, New York, pp 3-38

14. Black JE, Sirevaag AM, Greenough WT (1987) Complex experience promotes capillary formation in young rat visual cortex. Neurosci Lett 83(3):351-355

15. Black JE, Isaacs KR, Anderson BJ, Alcantara AA, Greenough WT (1990) Learning causes synaptogenesis, whereas motor activity causes angiogenesis, in cerebellar cortex of adult rats. Proc Natl Acad Sci U S A 87(14):5568-5572

16. Boyke J, Driemeyer J, Gaser C, Buchel C, May A (2008) Training-induced brain structure changes in the elderly. J Neurosci 28(28):7031-7035. doi:10.1523/JNEUROSCI.0742-08.2008

17. Carro E, Nunez A, Busiguina S, Torres-Aleman I (2000) Circulating insulin-like growth factor I mediates effects of exercise on the brain. J Neurosci 20(8):2926-2933

18. Caspersen CJ, Powell KE, Christenson GM (1985) Physical activity, exercise, and physical fitness: definitions and distinctions for health-related research. Public Health Rep 100(2):126-131

19. Cavanaugh JC (1990) The importance of awareness in memory aging. In: Poon LW, Rubin DC, Wilson BA (eds) Everyday cognition in adulthood and late life. Cambridge University Press, New York, pp 416-436

20. Chodzko-Zajko WJ (1991) Physical fitness, cognitive performance, and aging. Med Sci Sports Exerc 23(7):868-872

21. Chodzko-Zajko WJ, Moore KA (1994) Physical fitness and cognitive functioning in aging. Exerc Sport Sci Rev 22:195-220

22. Chodzko-Zajko WJ, Proctor DN, Fiatarone Singh MA, Minson CT, Nigg CR, Salem GJ, Skinner JS (2009) American College of Sports Medicine position stand. Exercise and physical activity for older adults. Med Sci Sports Exerc 41(7):1510-1530. doi:10.1249/MSS.0b013e3181a0c95c

23. Churchill JD, Galvez R, Colcombe S, Swain RA, Kramer AF, Greenough WT (2002) Exercise, experience and the aging brain. Neurobiol Aging 23(5):941-955

24. Colcombe S, Kramer AF (2003) Fitness effects on the cognitive function of older adults: a meta-analytic study. Psychol Sci 14 (2): $125-130$

25. Colcombe SJ, Erickson KI, Raz N, Webb AG, Cohen NJ, McAuley E, Kramer AF (2003) Aerobic fitness reduces brain tissue loss in aging humans. J Gerontol A Biol Sci Med Sci 58(2):176-180

26. Colcombe SJ, Erickson KI, Scalf PE, Kim JS, Prakash R, McAuley E, Elavsky S, Marquez DX, Hu L, Kramer AF (2006) Aerobic exercise training increases brain volume in aging humans. $\mathrm{J}$ Gerontol A Biol Sci Med Sci 61(11):1166-1170

27. Cotman CW, Berchtold NC (2002) Exercise: a behavioral intervention to enhance brain health and plasticity. Trends Neurosci 25 (6):295-301. doi:S0166223602021434

28. Der G, Deary IJ (2006) Age and sex differences in reaction time in adulthood: results from the United Kingdom Health and Lifestyle Survey. Psychol Aging 21(1):62-73. doi:10.1037/0882-7974.21.1.62

29. Dienstbier RA (1989) Arousal and physiological toughness: implications for mental and physical health. Psychol Rev 96 (1):84-100

30. Dienstbier RA (1991) Behavioral correlates of sympathoadrenal reactivity: the toughness model. Med Sci Sports Exerc 23 (7):846-852

31. Doidge N (2007) The brain that changes itself: stories of personal triumph from the frontiers of brain science. Viking, New York 
32. Draganski B, Gaser C, Busch V, Schuierer G, Bogdahn U, May A (2004) Neuroplasticity: changes in grey matter induced by training. Nature 427(6972):311-312

33. Dratcu L (2009) The future of depression: a complex neuroendocrine, inflammatory and neurodegenerative systemic illness. Vertex 20(87):329-341

34. Dustman R, White A (2006) Effects of exercise on cognition in older adults: A reexamination of proposed mechanisms. In: Poon LW, Chodzko-Zajko W, Tomporowski PD (eds) Active living, cognitive functioning and aging. Human Kinetics, Champaign, pp 51-74

35. Dustman R, Emmerson R, Schearer D (1994) Physical activity, age, and cognitive neuropsychological function. J Aging Phys Act 2(2): $143-181$

36. Edwards JD, Wadley VG, Vance DE, Wood K, Roenker DL, Ball KK (2005) The impact of speed of processing training on cognitive and everyday performance. Aging Ment Health 9(3):262271. doi:10.1080/13607860412331336788

37. Edwards JD, Myers C, Ross LA, Roenker DL, Cissell GM, McLaughlin AM, Ball KK (2009) The longitudinal impact of cognitive speed of processing training on driving mobility. Gerontologist 49(4):485-494. doi:10.1093/geront/gnp042

38. Endres M, Gertz K, Lindauer U, Katchanov J, Schultze J, Schrock H, Nickenig G, Kuschinsky W, Dirnagl U, Laufs U (2003) Mechanisms of stroke protection by physical activity. Ann Neurol 54(5):582-590. doi:10.1002/ana.10722

39. Era P, Jokela J, Heikkinen E (1986) Reaction and movement times in men of different ages: a population study. Percept Mot Skills 63(1):111-130

40. Erickson KI, Voss MW, Prakash RS, Basak C, Szabo A, Chaddock L, Kim JS, Heo S, Alves H, White SM, Wojcicki TR, Mailey E, Vieira VJ, Martin SA, Pence BD, Woods JA, McAuley E, Kramer AF (2011) Exercise training increases size of hippocampus and improves memory. Proc Natl Acad Sci USA 108(7):3017-3022. doi:10.1073/pnas.1015950108

41. Eriksson PS, Perfilieva E, Bjork-Eriksson T, Alborn AM, Nordborg C, Peterson DA, Gage FH (1998) Neurogenesis in the adult human hippocampus. Nat Med 4(11):1313-1317. doi:10.1038/3305

42. Etnier J (2008) Interrelationships of exercise, mediator variables, and cognition. In: Spirduso WW, Poon LW, Chodzko-Zajko (eds) Exercise and its mediating effects on cognition. Human Kinetics, Champaign, IL, pp 13-32

43. Etnier JL (2009) Physical activity programming to promote cognitive function: are we ready for prescription? In: Chodzko-Zajko WJ, Kramer AF, Poon LW (eds) Enhance cognitive functioning and brain plasticity. Human Kinetics, Champaign, pp 159-175

44. Etnier JR, Salazar W, Landers DM, Petruzzello SJ, Han M, Novell P (1997) The influence of physical fitness and exercise upon cognitive functioning: a meta analysis. J Sport Exerc Psychol 19:249-277

45. Etnier JL, Nowell PM, Landers DM, Sibley BA (2006) A metaregression to examine the relationship between aerobic fitness and cognitive performance. Brain Res Rev 52(1):119-130. doi:10.1016/j.brainresrev.2006.01.002

46. Fabre C, Chamari K, Mucci P, Masse-Biron J, Prefaut C (2002) Improvement of cognitive function by mental and/or individualized aerobic training in healthy elderly subjects. Int J Sports Med 23(6):415-421. doi:10.1055/s-2002-33735

47. Friedland RP (1990) Brain imaging and cerebral metabolism. In: Boller F, Grafman J (eds) Handbook of neropsychology. Elsevier Science, Amsterdam, pp 197-211

48. Garber CE, Blissmer B, Deschenes MR, Franklin BA, Lamonte MJ, Lee IM, Nieman DC, Swain DP, American College of Sports M (2011) American College of Sports Medicine position stand. Quantity and quality of exercise for developing and maintaining cardiorespiratory, musculoskeletal, and neuromotor fitness in apparently healthy adults: guidance for prescribing exercise. Med Sci Sports Exerc 43(7):1334-1359. doi:10.1249/ MSS.0b013e318213fefb

49. Gaser C, Schlaug G (2003) Brain structures differ between musicians and non-musicians. J Neurosci 23(27):9240-9245

50. Geerlings MI, Schoevers RA, Beekman AT, Jonker C, Deeg DJ, Schmand B, Ader HJ, Bouter LM, Van Tilburg W (2000) Depression and risk of cognitive decline and Alzheimer's disease. Results of two prospective community-based studies in The Netherlands. Br J Psychiatry 176:568-575

51. Gellatly I, Meyer J (1992) The effects of goal difficulty on physiological arousal, cognition, and task performance. J Appl Psychol 77:694-694

52. Ghisletta P, Bickel JF, Lovden M (2006) Does activity engagement protect against cognitive decline in old age? Methodological and analytical considerations. J Gerontol B Psychol Sci Soc Sci 61(5):253-261

53. Gould E, Beylin A, Tanapat P, Reeves A, Shors TJ (1999) Learning enhances adult neurogenesis in the hippocampal formation. Nat Neurosci 2(3):260-265. doi:10.1038/6365

54. Gould E, Reeves AJ, Graziano MS, Gross CG (1999) Neurogenesis in the neocortex of adult primates. Science 286 (5439):548-552

55. Gould E, Vail N, Wagers M, Gross CG (2001) Adult-generated hippocampal and neocortical neurons in macaques have a transient existence. Proc Natl Acad Sci USA 98(19):10910-10917. doi:10.1073/pnas. 181354698

56. Green CS, Bavelier D (2008) Exercising your brain: a review of human brain plasticity and training-induced learning. Psychol Aging 23(4):692-701. doi:10.1037/a0014345

57. Hartley A (2006) Changing role of the speed of processing construct in the cognitive psychology of human aging. In: Birren JE, Schaie KW (eds) Handbook of the psychology of aging, 6th edn. Elsevier Academic Press, Burlington, MA, pp 183-207

58. Hattori S, Naoi M, Nishino H (1994) Striatal dopamine turnover during treadmill running in the rat: relation to the speed of running. Brain Res Bull 35(1):41-49

59. Hawkins HL, Kramer AF, Capaldi D (1992) Aging, exercise, and attention. Psychol Aging 7(4):643-653

60. Izquierdo-Porrera AM, Waldstein SR (2002) Cardiovascular risk factors and cognitive function in African Americans. J Gerontol B Psychol Sci Soc Sci 57(4):377-380

61. Jacini WF, Cannonieri GC, Fernandes PT, Bonilha L, Cendes F, Li LM (2009) Can exercise shape your brain? Cortical differences associated with judo practice. J Sci Med Sport 12(6):688-690. doi:10.1016/j.jsams.2008.11.004

62. Jacobs B, Schall M, Scheibel AB (1993) A quantitative dendritic analysis of Wernicke's area in humans: II. Gender, hemispheric, and environmental factors. J Comp Neurol 327(1):97-111. doi:10.1002/cne.903270108

63. Kempermann G, Kuhn HG, Gage FH (1997) More hippocampal neurons in adult mice living in an enriched environment. Nature 386(6624):493-495. doi:10.1038/386493a0

64. Kempermann G, Kuhn H, Gage F (1998) Experience-induced neurogenesis in the senescent dentate gyrus. J Neurosci 18(9):3206

65. Kerr CE, Shaw JR, Wasserman RH, Chen VW, Kanojia A, Bayer T, Kelley JM (2008) Tactile acuity in experienced Tai Chi practitioners: evidence for use dependent plasticity as an effect of sensory-attentional training. Exp Brain Res 188(2):317-322. doi:10.1007/s00221-008-1409-6

66. Kleim JA, Lussnig E, Schwarz ER, Comery TA, Greenough WT (1996) Synaptogenesis and Fos expression in the motor cortex of the adult rat after motor skill learning. J Neurosci 16(14):4529-4535

67. Kleim JA, Vij K, Ballard DH, Greenough WT (1997) Learningdependent synaptic modifications in the cerebellar cortex of the adult rat persist for at least four weeks. J Neurosci 17(2):717-721 
68. Klintsova AY, Cowell RM, Swain RA, Napper RM, Goodlett CR, Greenough WT (1998) Therapeutic effects of complex motor training on motor performance deficits induced by neonatal binge-like alcohol exposure in rats: I. Behavioral results. Brain Res 800(1):48-61

69. Kozorovitskiy Y, Gross CG, Kopil C, Battaglia L, McBreen M, Stranahan AM, Gould E (2005) Experience induces structural and biochemical changes in the adult primate brain. Proc Natl Acad Sci U S A 102(48):17478-17482. doi:10.1073/pnas.0508817102

70. Kramer AF, Morrow D (in press) Cognitive training and expertise. In: Park D, Schwartz N (eds) Cognitive aging: a primer. Psychology Press, Philadelphia, PA

71. Kramer A, Larish J, Strayer D (1995) Training for attention control in dual task settings: a comparison of young and old adults. Journal of Experimental Psychology Applied 1:50-76

72. Kramer A, Larish J, Weber T, Bardell L (1999) Training for executive control: task coordination strategies and aging. In: Gopher D, Koriat A (eds) Attention and performance XVII. MIT Press, Cambridge, MA, pp 617-652

73. Kramer AF, Colcombe S, Erickson K, Belopolsky A, McAuley E, Cohen NJ, Webb A, Jerome GJ, Marquez DX, Wszalek TM (2002) Effects of aerobic fitness training on human cortical function: a proposal. J Mol Neurosci 19(1-2):227-231. doi: JMN:19:1-2:227.doi:10.1007/s12031-002-0038-y

74. Kramer AF, Colcombe SJ, McAuley E, Eriksen KI, Scalf P, Jerome GJ, Marquez DX, Elavsky S, Webb AG (2003) Enhancing brain and cognitive function of older adults through fitness training. J Mol Neurosci 20(3):213-221

75. Kramer A, Bherer L, Colcombe S, Dong W, Greenough W (2004) Environmental influences on cognitive and brain plasticity during aging. J Gerontol A Biol Sci Med Sci 59(9):M940

76. Kuramoto AM (2006) Therapeutic benefits of Tai Chi exercise: research review. Wisc Med Journal 105(7):42-46

77. Kutner NG, Barnhart H, Wolf SL, McNeely E, Xu T (1997) Selfreport benefits of Tai Chi practice by older adults. J Gerontol B Psychol Sci Soc Sci 52(5):242-246

78. Lobjois R, Benguigui N, Bertsch J, Broderick MP (2008) Collision avoidance behavior as a function of aging and tennis playing. Exp Brain Res 184(4):457-468. doi:10.1007/s00221-007-1117-7

79. Magill R (2003) Motor Learning and control, concepts and applications, 7th edn. McGraw-Hill, New York

80. Maguire EA, Gadian DG, Johnsrude IS, Good CD, Ashburner J, Frackowiak RSJ, Frith CD (2000) Navigation-related structural change in the hippocampi of taxi drivers. Proc Natl Acad Sci USA 97(8):4398

81. Manning CA, Ragozzino ME, Gold PE (1993) Glucose enhancement of memory in patients with probable senile dementia of the Alzheimer's type. Neurobiol Aging 14(6):523-528

82. Manning CA, Stone WS, Korol DL, Gold PE (1998) Glucose enhancement of 24-h memory retrieval in healthy elderly humans. Behav Brain Res 93(1-2):71-76

83. Marks BL, Katz LM, Nunley DC (2000) Cerebral blood flow and cognitive function is maintained in aerobically active older adults. Circulation 102:S4198

84. Marmeleira JF, Godinho MB, Fernandes OM (2009) The effects of an exercise program on several abilities associated with driving performance in older adults. Accid Anal Prev 41(1):90-97. doi:10.1016/j.aap.2008.09.008

85. Marmeleira JF, Soares de Melo FM, Tlemcani M, Godinho MA (2011) Exercise can improve speed of behavior in older drivers. J Aging Phys Act 19(1):48-61

86. McAuley E, Elavsky S (2008) Self-efficacy, physical activity, and cognitive function. In: Spirduso WW, Poon LW, Chodzko-Zajko (eds) Exercise and its mediating effects on cognition. Human Kinetics, Champaign, IL, pp 69-84
87. McAuley E, Jerome GJ, Elavsky S, Marquez DX, Ramsey SN (2003) Predicting long-term maintenance of physical activity in older adults. Prev Med 37(2):110-118

88. McFarland RA (1963) Experimental evidence of the relantioship between aging and oxygen want: In search of a theory of aging. Ergonomics 6:339-366

89. McMorris T (2009) Exercise and cognitive function: a neuroendocrinological explanation. In: McMorris T, Tomporowsky P, Audiffren M (eds) Exercise and cognitive function. Willey \& Blackwell, Chichester, West Sussex, UK, pp 41-68

90. Meeusen R (2005) Exercise and the brain: insight in new therapeutic modalities. Ann Transplant 10(4):49-51

91. Meeusen R, Smolders I, Sarre S, De Meirleir K, Keizer H, Serneels M, Ebinger G, Michotte Y (1997) Endurance training effects on neurotransmitter release in rat striatum: an in vivo microdialysis study. Acta Physiol Scand 159(4):335-341

92. Meeusen R, Piacentini MF, De Meirleir K (2001) Brain microdialysis in exercise research. Sports Med 31(14):965-983

93. Meyer JS, Terayama Y, Takashima S (1993) Cerebral circulation in the elderly. Cerebrovasc Brain Metab Rev 5(2):122-146

94. Mizoguchi K, Shoji H, Tanaka Y, Maruyama W, Tabira T (2009) Age-related spatial working memory impairment is caused by prefrontal cortical dopaminergic dysfunction in rats. Neuroscience 162(4):1192-1201. doi:10.1016/j.neuroscience.2009.05.023

95. Moss M, Franks M, Briggs P, Kennedy D, Scholey A (2005) Compromised arterial oxygen saturation in elderly asthma sufferers results in selective cognitive impairment. J Clin Exp Neuropsychol 27(2):139-150

96. Neeper SA, Gomez-Pinilla F, Choi J, Cotman C (1995) Exercise and brain neurotrophins. Nature 373(6510):109. doi:10.1038/ $373109 \mathrm{a} 0$

97. Nicoletti G, Arabia G, Pugliese P, Torchia G, Pucci F, Gambardella A, Quattrone A, Zappia M (2005) Movement time and aging: a normative study in healthy subjects with the "Movement Time Analyzer". Aging Clin Exp Res 17(3):207-210

98. Oman RF, King AC (1998) Predicting the adoption and maintenance of exercise participation using self-efficacy and previous exercise participation rates. Am J Health Promot 12(3):154-161

99. Oswald WD, Rupprecht R, Gunzelmann T, Tritt K (1996) The SIMA-project: effects of 1 year cognitive and psychomotor training on cognitive abilities of the elderly. Behav Brain Res 78 (1):67-72

100. Owsley C, Sloane M, McGwin G Jr, Ball K (2002) Timed instrumental activities of daily living tasks: relationship to cognitive function and everyday performance assessments in older adults. Gerontology 48(4):254-265

101. Panton LB, Graves JE, Pollock ML, Hagberg JM, Chen W (1990) Effects of aerobic and resistance training on fractioned reaction time and speed of movement. J Gerontol 45:M26-M31

102. Pereira AC, Huddleston DE, Brickman AM, Sosunov AA, Hen R, McKhann GM, Sloan R, Gage FH, Brown TR, Small SA (2007) An in vivo correlate of exercise-induced neurogenesis in the adult dentate gyrus. Proc Natl Acad Sci U S A 104(13):5638 5643. doi:10.1073/pnas.0611721104

103. Pesce C, Cereatti L, Casella R, Baldari C, Capranica L (2007) Preservation of visual attention in older expert orienteers at rest and under physical effort. J Sport Exerc Psychol 29(1):78-99

104. Poon LW, Harrington CA (2006) Commonalities in aging and fitness-related impact on cognition. In: Poon LW, Chodzko-Zajko W, Tomporowski PD (eds) Active living, cognitive functioning and aging. Human Kinetics, Champaign, pp 187-195

105. Rampon C, Tsien JZ (2000) Genetic analysis of learning behaviorinduced structural plasticity. Hippocampus 10(5):605-609

106. Rogers RL, Meyer JS, Mortel KF (1990) After reaching retirement age physical activity sustains cerebral perfusion and cognition. J Am Geriatr Soc 38(2):123-128 
107. Rosenzweig MR, Bennett EL (1996) Psychobiology of plasticity: effects of training and experience on brain and behavior. Behav Brain Res 78(1):57-65

108. Roth DL, Goode KT, Clay OJ, Ball KK (2003) Association of physical activity and visual attention in older adults. J Aging Health 15(3):534-547

109. Sachs-Ericsson N, Joiner T, Plant E, Blazer D (2005) The influence of depression on cognitive decline in community-dwelling elderly persons. American Journal of Geriatric Psych 13(5):402

110. Salthouse TA (1996) The processing-speed theory of adult age differences in cognition. Psychol Rev 103(3):403-428

111. Salthouse TA (2006) Mental exercise and mental aging evaluating the validity of the "use it or lose it" hypothesis. Perspect Psychol Sci 1(1):68-87

112. Scholey AB, Moss MC, Neave N, Wesnes K (1999) Cognitive performance, hyperoxia, and heart rate following oxygen administration in healthy young adults. Physiol Behav 67(5):783-789

113. Schooler C (2009) The effects of the cognitive complexity of occupational conditions and leisure-time activities on the intellectual functioning of older adults. In: Chodzko-Zajko W, Kramer A, Poon LW (eds) Enhancing cognitive functioning and brain plasticity, vol. 3. Human Kinetics, Champaign, IL, pp 15-34

114. Segovia G, del Arco A, Mora F (2009) Environmental enrichment, prefrontal cortex, stress, and aging of the brain. J Neural Transm 116(8):1007-1016. doi:10.1007/s00702-009-0214-0

115. Seidler RD, Bernard JA, Burutolu TB, Fling BW, Gordon MT, Gwin JT, Kwak Y, Lipps DB (2009) Motor control and aging: Links to age-related brain structural, functional, and biochemical effects. Neurosci Biobehav Rev. doi:10.1016/j.neubiorev.2009.10.005

116. Shay KA, Roth DL (1992) Association between aerobic fitness and visuospatial performance in healthy older adults. Psychol Aging 7(1):15-24

117. Slegers K, van Boxtel M, Jolles J (2006) Successful cognitive aging: the use of computers and the Internet to support autonomy in later life. Neuropsych Publishers, Maastricht

118. Slosman DO, Chicherio C, Ludwig C, Genton L, de Ribaupierre S, Hans D, Pichard C, Mayer E, Annoni JM, de Ribaupierre A (2001) (133)Xe SPECT cerebral blood flow study in a healthy population: determination of T-scores. J Nucl Med 42(6):864-870

119. Spirduso WW (1980) Physical fitness, aging, and psychomotor speed: a review. J Gerontol 35(6):850-865

120. Stranahan AM, Khalil D, Gould E (2006) Social isolation delays the positive effects of running on adult neurogenesis. Nat Neurosci 9(4):526-533. doi:10.1038/nn1668

121. Swaab DF (1991) Brain aging and Alzheimer's disease, "wear and tear" versus "use it or lose it". Neurobiol Aging 12(4):317-324

122. Swain RA, Harris AB, Wiener EC, Dutka MV, Morris HD, Theien BE, Konda S, Engberg K, Lauterbur PC, Greenough WT (2003) Prolonged exercise induces angiogenesis and increases cerebral blood volume in primary motor cortex of the rat. Neuroscience 117(4):1037-1046

123. Takada H, Nagata K, Hirata Y, Satoh Y, Watahiki Y, Sugawara J, Yokoyama E, Kondoh Y, Shishido F, Inugami A et al (1992) Agerelated decline of cerebral oxygen metabolism in normal population detected with positron emission tomography. Neurol Res 14 (2 Suppl):128-131

124. Thorndike E, Woodworth R (1901) The influence of improvement in one mental function upon the efficiency of other functions: II. The estimation of magnitudes. Psychol Rev 8(4):384-395

125. Tomporowski PD (1997) The effects of physical and mental training on the mental abilities of older adults. J Aging Phys Act 5:9-26
126. Tranter LJ, Koutstaal W (2008) Age and flexible thinking: an experimental demonstration of the beneficial effects of increased cognitively stimulating activity on fluid intelligence in healthy older adults. Neuropsychol Dev Cogn B Aging Neuropsychol Cogn 15(2):184-207. doi:10.1080/13825580701322163

127. van Boxtel MP, Paas FG, Houx PJ, Adam JJ, Teeken JC, Jolles J (1997) Aerobic capacity and cognitive performance in a crosssectional aging study. Med Sci Sports Exerc 29(10):1357-1365

128. van Praag H (2008) Neurogenesis and exercise: past and future directions. Neuromolecular Med 10(2):128-140. doi:10.1007/ s12017-008-8028-z

129. van Praag H, Christie BR, Sejnowski TJ, Gage FH (1999) Running enhances neurogenesis, learning, and long-term potentiation in mice. Proc Natl Acad Sci USA 96(23):13427-13431

130. van Praag H, Kempermann G, Gage FH (2000) Neural consequences of environmental enrichment. Nat Rev Neurosci 1 (3):191-198

131. van Praag H, Shubert T, Zhao C, Gage FH (2005) Exercise enhances learning and hippocampal neurogenesis in aged mice. J Neurosci 25(38):8680-8685. doi:10.1523/JNEUROSCI.173105.2005

132. Vaynman S, Ying Z, Gomez-Pinilla F (2004) Hippocampal BDNF mediates the efficacy of exercise on synaptic plasticity and cognition. Eur J Neurosci 20(10):2580-2590. doi:10.1111/ j.1460-9568.2004.03720.x

133. Voss M, Kramer A, Basak C, Prakash R, Roberts B (2009) Are expert athletes expert in the cognitive laboratory? A meta-analytic review of cognition and sport expertise. Appl Cognitive Psych 24 (6):812-826. doi:10.1002/acp.1588

134. Willis SL, Tennstedt SL, Marsiske M, Ball K, Elias J, Koepke KM, Morris JN, Rebok GW, Unverzagt FW, Stoddard AM, Wright E (2006) Long-term effects of cognitive training on everyday functional outcomes in older adults. JAMA 296 (23):2805-2814. doi:10.1001/jama.296.23.2805

135. Winter B, Breitenstein C, Mooren FC, Voelker K, Fobker M, Lechtermann A, Krueger K, Fromme A, Korsukewitz C, Floel A, Knecht S (2007) High impact running improves learning. Neurobiol Learn Mem 87(4):597-609. doi:10.1016/ j.nlm.2006.11.003

136. Wolinsky FD, Unverzagt FW, Smith DM, Jones R, Stoddard A, Tennstedt SL (2006) The ACTIVE cognitive training trial and health-related quality of life: protection that lasts for 5 years. $\mathrm{J}$ Gerontol A Biol Sci Med Sci 61(12):1324-1329

137. Wolinsky FD, Unverzagt FW, Smith DM, Jones R, Wright E, Tennstedt SL (2006) The effects of the ACTIVE cognitive training trial on clinically relevant declines in health-related quality of life. J Gerontol B Psychol Sci Soc Sci 61(5):S281-S287

138. Yerkes RM, Dodson JD (1908) The relation of strenght of stimulus to rapidity of habit-formation. J Comp Neurol Psychol $18: 459-482$

139. Zheng H, Liu Y, Li W, Yang B, Chen D, Wang X, Jiang Z, Wang H, Wang Z, Cornelisson G, Halberg F (2006) Beneficial effects of exercise and its molecular mechanisms on depression in rats. Behav Brain Res 168(1):47-55. doi:10.1016/j.bbr.2005.10.007

140. Zoladz JA, Pilc A, Majerczak J, Grandys M, Zapart-Bukowska J, Duda K (2008) Endurance training increases plasma brainderived neurotrophic factor concentration in young healthy men. J Physiol Pharmacol 59(Suppl 7):119-132

141. Zunzunegui M, Alvarado B, Del Ser T, Otero A (2003) Social networks, social integration, and social engagement determine cognitive decline in community-dwelling Spanish older adults. J Gerontol B Psychol Sci Soc Sci 58(2):93 